\title{
Dialectical Relevance in Persuasion Dialogue
}

\section{Douglas Walton University of Winnipeg}

\begin{abstract}
How to model relevance in argumentation is an important problem for informal logic. Dialectical relevance is determined by the use of an argument for some purpose in different types of dialogue, according to the new dialectic. A central type of dialogue is persuasion dialogue in which one participant uses rational argumentation to try to get the other participant to accept a designated proposition. In this paper, a method for judging relevance in persuasion dialogue is presented. The method is based on using the technique of argument diagramming.
\end{abstract}

Résumé: L'explication de la pertinence dans l'argumentation est un problème important de la logique non formelle. Selon la nouvelle dialectique, la pertinence dialectique se délimite par l'usage et le but d'un argument dans différents types de dialogue. Un exemple principal de ceux-ci est le dialogue de persuasion dans lequel on emploie l'argumentation rationnelle pour convaincre une autre personne d'accepter une proposition particulière. Dans cet article on emploie la technique des diagrammes des arguments pour decrire une méthode d'évaluer la pertinence dans les dialogues de persuasion.

Keywords: argument chaining, fallacy of irrelevant conclusion, ignoratio elenchi, political debating, rhetorical argument, rules of parliamentary debate, argument diagramming, pathway of reasoning, material relevance.

A method is presented here for testing an argument for dialectical relevance or irrelevance. 'The term 'dialectical' (Hamblin, 1970; van Eemeren and Grootendorst, 1984; Freeman, 1991) refers to the use of an argument in a context of dialogue, or goal-directed conversational exchange of viewpoints. ${ }^{2}$ The particular type of dialogue in which dialectical relevance is modeled here is the persuasion dialogue (Walton, 1989), where the goal of each participant is to persuade the other party that a particular proposition (the arguer's thesis to be proven) is acceptable as a commitment. ${ }^{3}$ The main idea of the investigation is to use the conditions for a proper persuasion dialogue as a means of clarifying the idea of dialectical relevance. A method of argument extrapolation is devised to test an argument given in a particular case, to determine if it meets the requirements of relevance appropriate for a persuasion dialogue.

Two cases are used to illustrate the application of the test. One is a classical case used in a logic textbook (Copi, 1982) to illustrate the fallacy of irrelevant conclusion. The other is an argument used in an actual case-a political debate in the Canadian House of Commons. The practical problem addressed is how criti- 
cisms of irrelevance should be evaluated by a set of precisely formulated rules in particular cases like these. But it is also shown how this set of rules can be formalized, providing a core structure of persuasion dialogue. And it is shown how this core structure can be implemented as a dialogue system for artificial intelligence uses.

\section{Persuasion Dialogue}

The elements of a persuasion dialogue are two participants, called the proponent and the respondent, and two propositions (statements). One proposition is the thesis of the proponent and the other proposition is the thesis of the respondent. The two theses stand in a relation of opposition to each other. The strongest form of opposition of a pair of propositions is that of contradictoriness (negation), meaning that the one proposition is true if and only if the other is not true. Both participants have the same goal-to prove their own thesis from the commitments of the other party.

The type of persuasion dialogue described above could be called a dispute, meaning that it is a symmetrical type of dialogue where the arguments of the one party are opposed to that of the other, and each side has a burden of proof to prove a designated proposition. There can also be another type of persuasion dialogue where the goals of the two parties are different. The proponent, to be successful, must prove her thesis, where the respondent, to be successful only has to raise questions about the proponent's attempted proof that throw doubt on it, showing that it has not been successful. ${ }^{4}$

The essential characteristic of persuasion dialogue, according to Walton (1989, pp. 4-10) is that the arguments used by both parties must be based on premises that are commitments of the other party. In a Hamblin structure of formal dialectic (Hamblin, 1970, p. 257), each participant in a dialogue has a commitment set, a set of propositions that keep a running tally of an arguer's commitments. As each speaker makes a move in the dialogue, propositions are added to or deleted from this set, depending on the type of move made. For example, if a particular proposition is asserted at some move by a participant, then that proposition is added to her commitment set.

Basically, in a persuasion dialogue, two arguers ask questions and put arguments to each other, where the aim is to get the other party to become committed to propositions that can be used to prove one's own thesis by a connected chain of argumentation. Each individual inference in the chain is supposed to be valid, or structurally correct, according to the forms of argument appropriate for use in this type of dialogue.

One particular type of persuasion dialogue is the critical discussion, where the goal is to resolve a conflict of opinions by rational argumentation (van Eemeren and Grootendorst, 1984; 1992). A successful critical discussion, according to van Eemeren and Grootendorst (1984, p. 86) ends with a resolution of the conflict, 
and otherwise it is "not clear whether the discussion has had any point." But in types of persuasion dialogue other than a critical discussion, the dialogue may be regarded as successful if the conflict is not resolved, but the discussion has thrown light on the issue by revealing new commitments through strong and persuasive arguments that make the viewpoints on both sides more sophisticated and less susceptible to refutation-see the discussion of the maieutic function of persuasion dialogue in (Walton and Krabbe, 1995).

In a persuasion dialogue, various kinds of moves are allowed, including the asking of questions, the answering of these questions, and the putting forward of arguments. When it comes to the putting forward of arguments, there are four basic requirements that determine what is an argument that has been used successfully and appropriately by a proponent in the dialogue, to prove a conclusion.

(R1) The respondent accepts the premises as commitments.

(R2) Each inference in the chain of argument is structurally correct.

(R3) The chain of argumentation must have the proponent's thesis as its (ultimate) conclusion.

(R4) Arguments meeting (R1), (R2), (R3) and (R4) are the only means that count as fulfilling the proponent's goal in the dialogue.

Some possible exceptions to these rules of a rational argument-discussed in Hamblin (1970, Chapter 7) and Walton (1996, Chapter 1)-concern hypothetical uses of arguments. We sometimes use arguments that are hypothetical in the sense that the premises are not commitments of the respondent, at least right now, but are propositions that the respondent might concede provisionally, or "for the sake of argument," as assumptions (or presumptions). This practice seems to violate (R1), but really it does not, because in the end, for an argument to count as rationally persuasive to a respondent, it must be based on premises that he has come to accept (as commitments) in the dialogue."

What is meant by (R2) is that an argument is structurally correct if the conclusion follows from the premise as an instance of a type of argument recognized by the participants in the dialogue. The appropriate rules of inference could be a set of rules for deductive logic, like propositional calculus. But the kinds of inference structures representing forms of argument most often used in presumptive reasoning are called argumentation schemes (Walton, 1996a).

Requirements (R3) and (R4) are closely related to the concept of dialectical relevance in argumentation, and need to be discussed in this light.

Two objections to the plan above are now stated and replied to.

Objection 1: Premises that a respondent accepts as commitments may fail to prove the conclusion that the respondent intends to establish on their basis even if each inference in the chain of argumentation is structurally correct, because these premises may be false or defective. Therefore requirements (R1) to (R4) are not jointly sufficient for proof. 
Reply: Three points need to be made in reply. First, the persuasion dialogue is an acceptance-based model of argumentation. One party can rationally persuade the other party to accept, or become committed to a proposition even though the proposition may not be true, or known to be true, established beyond doubt as true, etc. Retraction of commitment in a persuasion dialogue is generally possible, although not under all conditions (see Walton and Krabbe, 1995). Second, persuasion dialogue is not the only type of dialogue that represents the notion of proofit is possible to have other frameworks of dialogue in which argumentation takes place, and is used to prove a conclusion see (Walton, 1998). Third, there are different types of persuasion dialogue. For the example, the critical discussion is just one type of persuasion dialogue with very special requirements that define it, namely the ten rules of van Eemeren and Grootendorst (1987). (R1) through (R4) are not all the rules of any particular type of persuasion dialogue. They are postulated as mininal core requirements that are taken to be necessary (but not sufficient) for correct argumentation in any of these types of persuasion dialogue. Thus (R1) through (R4) are not meant to be jointly sufficient for proof. They are meant to be necessary requirements for an argument to be rationally persuasive.

Objection 2: How can we know that for an argument to count as rationally persuasive to a respondent is the same thing as for an argument to be used successfully by a proponent in a persuasion dialogue? Before we can proceed any further, it needs to be shown that these are the same thing.

Reply: The problem with this objection is that it demands that what is required to be proved, instantly proved at the outset. The critical discussion with its ten rules, as constructed by van Eemeren and Grootendorst, purports to meet the kind of criterion required by this objection. But it is not a formalized model. The problem then is to see if we can take some minimal requirements of a kind that can be formalized, namely rules (R1) through (R4), and see what needs to be added to them, in manageable increments, to work towards something like the type of dialogue that van Eemeren and Grootendorst have in mind, or other types of persuasion dialogue like the ones in (Walton and Krabbe, 1995). The proposed project is to break the problem down into a sequence of smaller, manageable steps. The objection misunderstands the nature of the problem, demanding an immediate solution in one single giant step. It says, "You are not allowed to go any further in the investigation until you immediately present the outcome, right away at the beginning". Instead of simply giving up at the outset in the face of this stultifying objection, the investigation needs to press on, to explore whether in fact (R1) through ( $R 4$ ) do represent some minimal notion of persuasion, and to consider what other requirements need to be added to them. The problem is that there are other requirements that can plausibly be added, but these additional rules are even more problematic to formalize, or express in any precise way, than (R1) through (R4). Hence the procedure of investigation adopted here is to begin with these four core requirements, and see how they can be stated in a precise way that can 
be formalized. The next phase of the program is to consider how various additional requirements can be added on.

\section{Chaining of Arguments}

(R2) and (R3) depend on the possibility of chaining together a sequence of inferences in argumentation. This idea is familiar in work on artificial intelligence, where so-called "forward chaining" and "backward chaining" are common features of how reasoning is done using premises in a data base. To take a simple example, take a modus ponens-type of inference based on a rule (or conditional proposition, as it is called in logic) and a fact (or simple proposition).

(I1) If $A$ then $B$

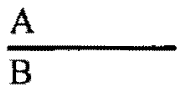

This inference can be "chained together" with another one-say, for example (12).

(I2) If $\mathrm{B}$ then $\mathrm{C}$

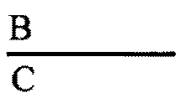

The two inferences, (I1) and (I2), can be chained together in a longer sequence of argumentation, because the conclusion of (I1), namely the simple proposition B can be utilized as a premise in (I2).

The simple example, above, would be a case of forward chaining of an argument, because the line of argument "moves forward" to prove the ultimate conclusion, $\mathrm{C}$. But in so-called abductive inference sequences in artificial intelligence, the user (or the system) is given the conclusion, C, and has to "reason backwards" to determine the premises that $C$ was based on (Josephson and Tanner, 1984).

Such chaining together of sub-arguments into a longer chain of argumentation is also a familiar phenomenon in critical thinking (informal logic) techniques of argument diagramming. Here the so-called "serial argument" is a chaining together of two arguments, where the conclusion of one functions as a premise in the next one-just as in the kind of example sketched out above (Walton, 1996, pp. 89-91). Such a chaining of argumentation can be modeled as a pathway of reasoning in an argument diagram (of the kind familiar in informal logic), using the new method of argument diagramming in (Walton, 1996, chapter 6). In this method, a line of reasoning is an alternating sequence of propositions and inference-steps where each step goes from one proposition to the next (see the formal definition in Walton, 1996, p. 189). A pathway of reasoning is a line of reasoning in which all the propositions are distinct (p. 189). A pathway of reasoning, in other words, is a line of reasoning in which there is no circular line of reasoning. The pathway of reasoning gives a picture of where an argument is going, looking at the argumentation in a global perspective, and not just as a single step of inference. 
In a persuasion dialogue, in any given case, you can view the argumentation on one side as a connected chain of argumentation that (ideally) uses only premises accepted by the other side, and that has a particular proposition as the ultimate conclusion at the end of the chain. This proposition is the thesis that the participant on this side of the dispute is supposed to prove. In a persuasion dialogue, this proposition is designated prior to the argumentation stage of the dialogue (at the so-called confrontation stage, where the theses of the both sides are identified). Once this proposition is identified for a participant, it provides a target, towards which all of her arguments are to be directed, as her ultimate conclusion to be proved. This chaining together of the argumentation on one side of a persuasion dialogue, and the directedness of the chain towards a single proposition, is an ideal of the successful (functional, appropriate) use of argumentation in this type of dialogue that provides a normative requirement to help us judge, in a given case, what is or is not a good (correct, appropriate) argument in this context of use. A good (useful) argument is one that fits into such a chain as a sub-argument of the longer chain that culminates in the arguer's thesis.

Not only is the idea of the chaining of arguments a clear and well-defined structure that can easily be modelled by the current technology in use in artificial intelligence, but all the other requirements of the persuasion dialogue, (R1), (R2) and (R4) are also easily modelled using this technology. The commitment set is just a set of propositions that can easily be modelled as a set of propositions in a computer data-base. How the commitment set is managed, by inserting propositions into it, and deleting propositions from it, at each move in a dialogue exchange, is clearly described by Hamblin $(1970 ; 1971)$. There are problems here. The most difficult one is to define the conditions under which retractions of commitments should be allowed. But these problems have been dealt with in Walton and Krabbe (1995) by constructing several different formal models of persuasion dialogue that have rules of retraction appropriate for the rigor or permissiveness of the dialogue exchange. Within this framework, persuasion dialogues meeting the requirements (R1) to (R4) can be formalized as clearly defined logical structures.

In the formal system of persuasion dialogue $\mathbf{P P D}_{0}$ constructed by Walton and Krabbe (1995, pp. 149-154), there are four kinds of rules. Locution rules indicate the types of permissible moves. Commitment rules govern the insertion and deletion of propositions from commitment sets. Structural rules define turn taking, and which types of moves can or must follow other moves. Win and loss rules define the participants' goals in the dialogue, and what counts as a sequence of moves that successfully fulfills one of these goals. One of the kinds of moves allowed in $\mathbf{P P D}_{0}$ is an elementary argument (p. 128), which is essentially a local argument, e.g., of the form modus ponens, of the kind so familiar as the standard kind of argument treated in logic textbooks. These elementary arguments can be

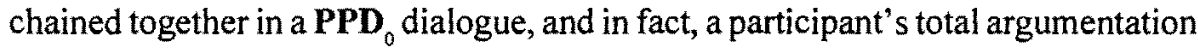
in support of her thesis can, at the concluding stage of a persuasion dialogue of this type, be seen as a lengthy chain of (hopefully) connected elementary argu- 
ments. So argumentation chaining is modelled in a $\mathbf{P P D}_{0}$ type of formal dialogue structure. And a $\mathbf{P P D}_{0}$ dialogue is the kind of structure in which all four of the requirements (R1) to (R4) are appropriate.

In any given case, if we view an argument as supposedly a contribution to a persuasion dialogue, then the presumption is that the proponent of the argument has a thesis that is supposed to be proved (or to be questioned or refuted). This thesis to be proved provides an end point, towards which the proponent's argument should be aimed. If it shows evidence of not really being aimed at this end point, but instead goes off in a different direction that only appears, superficially or to some extent to do so, it should be open to criticism on the grounds that it may be committing a fallacy of irrelevant conclusion. In evaluating any given case, the critic conducting the evaluation needs to look back, and ask what the original thesis was that the proponent was supposed to prove. Then the critic needs to look at the actual sequence of argumentation in the case, and judge to what extent it goes towards the proving or supporting of that original thesis. The normative requirement of a persuasion dialogue is that such a thesis exists, and that both parties have agreed that it will represent the issue to be decided by the argumentation in the dialogue.

\section{Rules of Dialogue and Fallacies}

Our goal in this exercise is to see how the persuasion dialogue as a structure, having only the requirements (R1) to (R4) imposed on it, can provide a useful normative structure for modelling dialectical relevance. Dialectical relevance is the kind of relevance that is appropriate when one speaks of arguments, or other moves made in argumentation (like the asking of questions), that are perceived as being logically or critically deficient, in some sense: as arguments or moves that should be subject to criticism. But once we bring in this negative idea of irrelevance as a failure of rational argumentation, we are in the realm of the traditional informal fallacies, many of which have standardly been portrayed in the logic textbooks as failures of relevance. ${ }^{6}$

The proposal that dialectical irrelevance is a logical defect of argumentation raises questions about how to define the range of the defect, leading to the following objection.

Objection 3: If dialectical relevance is defined broadly enough, any defect in argument could be a failure of dialectical relevance. If an argument has premises that are known to be false, this represents a kind of defect in the argument. But false premises may be relevant to the conclusion for which they are offered as support. Reason: if these premises were true, their truth would count in favor of the truth of the conclusion. So what are we to say about an argument in which the premises are known to be false? Are such premises relevant, or do they involve a failure of dialectical relevance? If so, the notion of dialectical relevance is obscure, and too broad. If not, an argument may have a failure other than that of dialectical relevance. 
Reply: The issue of false premises has already been discussed in the reply to Objection 1. But objection 3 adds another dimension, by questioning how relevance (and irrelevance) should be defined in relation to (R1) through (R4). It seems that (R2) and (R3) define relevance, whereas (R1) is a question of the status of the premises of an argument. (R1) has to do with whether the premises are accepted by the respondent. (R2) and (R3) have to do with the chain of argumentation leading from these premises, and whether that chain has the ultimate conclusion to be proved in the dialogue as its end point. In other words, there are two separate questions. One question is what are the starting points or premises of an argument, including their status as commitments. The other is the question of where these premises are leading. Are they leading in a line of argument towards the conclusion to be proved? The latter question rests on the presumption that in a persuasion dialogue, there is an ultimate conclusion-a proposition to be proved by one side, and to be questioned, thrown into doubt or disproved by the other side. This second question is the question of dialectical relevance. In reply to Objection 3 then, an important distinction should be made between dialectical irrelevance and another kind of logical defect that can occur in arguments. This other defect has to do with the status of the premises themselves, as propositions that can be supported or defended as commitments.

To get a more useful account of precisely what kind of logical failure irrelevance is, a connection needs to be made with the literature on the traditional informal fallacies. Van Eemeren and Grootendorst $(1984 ; 1987 ; 1992)$ have already made this connection, by advocating the theory that fallacies are violations of the rules of a critical discussion. There is in fact a striking connection between (R1) and the theory of van Eemeren and Grootendorst. According to the third rule for a critical discussion stated by van Eemeren and Grootendorst (1987; p. 286), an attack on a point of view (standpoint) must "relate to the standpoint that has really been advanced by the protagonist." Violations of rule three cited by van Eemeren and Grootendorst (1987, p. 286) are "imputing a fictitious standpoint to someone" and "distorting someone's standpoint." According to van Eemeren and Grootendorst, these violations of Rule Three correspond to the straw man fallacy, the fallacy of refuting an opponent's argument by setting up an exaggerated or distorted version of that opponent's standpoint (thesis being advocated), and then demolishing this phony version, thereby claiming to have refuted the opponent's argumentation. A familiar kind of example would be the case of a critic who claims to refute an environmentalist position by painting it as "having the ideal of making the world a parkland," and then criticizing this ideal as hopelessly impractical. Hence we can see from the theory of van Eemeren and Grootendorst, how the rules of a critical discussion can have normative bite in evaluating argumentation, and how violations of such rules can be associated with certain traditional informal fallacies.

What about modeling relevance then? Are certain rules for the critical discussion of a type that would be associated with dialectical relevance of argumenta- 
tion? The fourth rule of the critical discussion (van Eemeren and Grootendorst, 1987 , p. 286) stipulates that a party's point of view may be defended only by advancing arguments that are related to that point of view. The actual wording of the rule is: "A standpoint may be defended only by advancing argumentation relating to that standpoint." The question is how to interpret this rule exactly in a way that could be modelled in a formal structure of persuasion dialogue. In particular the question is one of how to interpret the expression 'relating to.' It seems fair to interpret this rule as essentially requiring relevance of argumentation in a critical discussion.

Objection 4: The above analysis interprets 'relating to' in terms of relevance, when it is said that the rule of van Eemeren and Grootendorst requires relevance. But then the analysis interprets relevance in terms of 'relating to'. This account is circular.

Reply: Yes, there is a circularity here, due to the yet-undefined nature of the terms used. But there is independent evidence that what van Eemeren and Grootendorst mean by 'relating to' does refer to the kind of relevance that is significant in connection with informal fallacies (see van Eemeren and Grootendorst, 1992a). In the end, this verbal question of whether the term 'relevance' or 'relating to' should be used is less important than the problem of trying to give some precise account of what either or both terms mean in relation to fallacies of irrelevance. But also, there is evidence for the hypothesis that the term 'relating' in van Eemeren and Grootendorst's rule refers to relevance. This hypothesis is supported by the two kinds of violations of the rule cited by van Eemeren and Grootendorst (1987, p. 247). One kind of violation occurs where "the argumentation does not refer to the standpoint under discussion," as in the case of "irrelevant argumentation" or ignoratio elenchi. The other kind of violation occurs where "the standpoint is defended by rhetorical ruses instead of argumentation," as in pathos, or "playing on the emotions or prejudices of the audience." Both fallacies are portrayed by van Eemeren and Grootendorst as being failures of relevance.

These descriptions of violations cited by van Eemeren and Grootendorst will turn out to correspond quite well to the examples we now turn to study-cases of the traditional fallacy of irrelevant conclusion, of the kind cited in the traditional accounts of fallacies in the logic textbooks. It seems fair to say then that the fourth rule of the critical discussion is a requirement that is meant to ensure that the argumentation in a critical discussion is in some sense relevant-relevant in the sense that the argumentation used must "relate" to the standpoint that is supposed to be argued for by a protagonist in such a discussion.

The problem is that irrelevance could take many forms in argumentation, and in fact, many fallacies are classified by logic textbooks like Copi (1982) as fallacies of relevance. Indeed, the catch-phrase "failure of relevance" has become such a widely used, but unexplained, device for declaring arguments of many different kinds fallacious that Hamblin (1970, p. 31) calls it a "rag-bag" category. 


\section{Douglas Walton}

The basic problem is that relevance has never really been defined by the logic textbooks in any more than various ad hoc and unhelpful ways that have never been based on any real theory of relevance. Sperber and Wilson (1986) have defined a kind of relevance, of a sort that refers to the information content of a proposition, but there is no indication whether or how this type of relevance applies to argumentation in a persuasion dialogue. Dascal (1977) and Berg (1991) have cited various kinds of relevance that might prove useful for purposes of evaluation of argumentation, but none of these kinds of relevance has been expressed in a formal structure or general theory. The formal systems of relevance logic that have been developed capture the idea of topical relevance, but not the idea of dialectical relevance (Walton, 1982).

\section{The Fallacy of Irrelevant Conclusion}

Many logic textbooks have traditionally described the "fallacy of irrelevant conclusion" as the device in argumentation of presenting an argument that may be valid (or otherwise correct), but that arrives at a conclusion other than the one that was supposed to be proved. For example, Jevons $(1878$, p. 178) defined the fallacy of irrelevant conclusion as "arguing to the wrong point, or proving one thing in such a manner that it is something else that is proved." Fowler (1895, p. 149) described "the fallacy of irrelevancy" as being committed by the person "who in a disputation does not confine himself to proving the contradictory or contrary of his adversary's assertion," but who proves some other proposition instead. Although many other kinds of fallacy of relevance are described by the logic textbooks, this particular one (based on Aristotle's fallacy of ignoratio elenchi, or "ignorance of refutation") has a place of central importance. Aristotle, in On Sophistical Refutations (167a22-167a36), following the translation of Hamblin $(1970$, p. 87), gave a very broad account of the fallacy of misconception of refutation (ignoratio elenchi). As Hamblin showed (1970, p. 105), Aristotle's account of this single fallacy encapsulates a virtually complete doctrine of fallacy. This broad and many-pronged account confused subsequent commentators, leading to the "rag-bag" problem. But there is also a more specific account of the fallacy of misconception of refutation in the Topics (162a13-162al6), where Aristotle describes an irrelevant argument as an argument that leads to something other than the conclusion it is supposed to prove. It is this more specific type of fault that is so often taken as the main fallacy of relevance in (often called the fallacy of wrong conclusion, or the fallacy of irrelevant conclusion) by the logic textbooks, over the ages. A leading case in point is the widely used introductory logic textbook of Copi (1982).

Copi (1982, p. 110) gives the following account of the fallacy of irrelevant conclusion, including a standard example that is very useful as a focus for discussing dialectical relevance. 


\section{Dialectical Relevance in Persuasion Dialogue}

Ignoratio Elenchi (irrelevant conclusion). The fallacy of ignoratio elenchi is committed when an argument purporting to establish a particular conclusion is directed to proving a different conclusion. For example, when a particular proposal for housing legislation is under consideration, legislators may rise to speak in favor of the bill and argue only that decent housing for all the people is desirable. Their remarks are then logically irrelevant to the point at issue, for the question concerns the particular measure at hand. Presumably everyone agrees that decent housing for all the people is desirable (even those will pretend to agree who do not really think so). The question is, Will this particular measure provide it and if so, will it provide it better than any practical alternative? The speakers' arguments are fallacious, for they commit the fallacy of ignoratio elenchi, or irrelevant conclusion.

According to Copi's explanation of how this fallacy works as a tactic of deceptive argument, one must contrast logical relevance and psychological relevance. The legislator's remarks about the desirability of decent housing for all the people are "logically irrelevant," according to Copi $(1982$, p. 110), but they "may succeed in evoking an attitude of approval for oneself and what one says." This positive attitude may then be transferred to the conclusion of the speaker's argument by the audience who hears the speech. So the legislator's remarks could be psychologically relevant, in the sense that such a transference takes place by "psychological association," as opposed to "logical implication" (p. 111).

The main problem with the kind of example cited by Copi is to understand the meaning of the concept of logical irrelevance, in virtue of which the legislator in the example can be criticized for having committed the fallacy of irrelevant conclusion. The basic failure, as described by Copi, is that the argument purports to establish a particular conclusion but "is directed to proving a different conclusion." This account of the failure suggests that the nature of the logical irrelevance committed by the legislator can be explained as a failure to meet requirement (R3) of a persuasion dialogue. The fault was (a) that the legislator's argument failed to have the proposition he was supposed to prove (his thesis in the persuasion dialogue) as the conclusion of his argument, and (b) he directed his argument toward proving a different conclusion. Feature (a) could be described as a failure to meet (R3), and feature (b) is an instance of a proponent's using some means to (apparently) fulfill her goal in a persuasion dialogue, other than the proper kind of means required by (R3). Hence the kind of logical (or dialectical) irrelevance that is the root of the problem of evaluating the fallacy of irrelevant conclusion in Copi's kind of case can be explained as a failure of good (correct, appropriate) use of argumentation by requirement (R3) of the persuasion dialogue. But while (R3) pinpoints the crux of the fault, a deeper explanation of the fallacy is helpful as well, which involves (R1), (R2) and (R4). The legislators' argument was that decent housing for all the people is desirable. This argument may very well have met requirements (R1) and (R2). It may have been based on premises that even the opponents of the bill would accept. It may have been composed of chain of infer- 
ences on which each sub-inference is structurally correct. An since it was on the topic of housing, it may have looked like it met (R3). And since it looked like it met all the three other requirements, therefore it may have looked like it met (R4) as well. Why would the argument look relevant, generally? One reason is that is, in at least one important sense, relevant.

The legislator's argument is, in at least one significant sense, logically relevant to the conclusion he is supposed to prove. When the legislator argues "Decent housing for all the people is desirable," this proposition is topically relevant to the conclusion he is supposed to prove, namely that the proposal for housing legislation is a good measure that ought to be voted for. The two propositions are topically relevant in the sense (Walton, 1982) that both share some common subjectmatters. For example, both contain the subject-matter of "housing." Topical relevance is one kind of logical relevance. The problem is not that the legislator's argument is totally irrelevant, in every respect that is logically significant, from the conclusion he is supposed to prove. The problem relating to the fallacy is that his argument fails to be materially relevant to this conclusion, meaning that it is part of a chain of argumentation that really is useful for proving this conclusion (as far as one can tell, from the details of the case given). It fails to be materially relevant, as well as dialectically irrelevant, because it fails to meet requirement (R3). But because it may either meet or appear to meet all of the other three requirements, it has an appearance or semblance of being relevant.

A practical problem is how to prove material relevance or irrelevance of an argument, as used in a given case like this example. The legislator's argument is used in medias res, in the middle of an ongoing legislative debate. How do we know that somehow he might not, in his subsequent chain of argumentation, use the premise, "Decent housing for all the people is desirable," as part of a materially relevant argument to support the conclusion that the housing bill he advocates is a good piece of legislation? The problem is that we really do not know this not to be the case, from the information given. It is only an assumption we make, from what we are told about the nature and direction of his argument. Once the debate is over, and we have a transcript of all that was said, it could be possible to document the claim that the legislators' argument fell short of its ultimate conclusion to be proved. But during the debate, if criticized for committing the fallacy of irrelevant conclusion, the legislator might reply, "If you just give me a little more latitude, I think I can show where my argument is leading, and why it is relevant." The speaker of the house would then have to judge whether more time should be given. In short, there is a practical problem of judging relevance in particular cases, especially when all the evidence may not yet be in. This same kind of practical problem is routinely dealt with in legal argumentation by judges in trials. One counsel may object that the opposing counsel's line of argument is irrelevant. The opposing counsel may ask for latitude, so she can show how her argument will turn out to be relevant. The judge will have to decide how to rule. According to the analysis proposed below, what the judge does, or should do, can be viewed 
as a chaining forward of the line of argumentation from the point where it is now at in the case. The question is whether such a chaining can go forward far enough to have the counsel's thesis to be proved as its ultimate conclusion. If so, the counsel's argument is relevant. Otherwise it is not. What the counsel's thesis is supposed to be is set by the burden of proof in the trial.

The other problem is that the argument in Copi's example is part of a political debate - a context of dialogue that is difficult to classify exactly. Argumentation in a political debate is not as highly structured as argumentation in a legal trial. The problem is that such a debate is not necessarily a persuasion dialogue at all. Or if it is partly a persuasion dialogue, it may equally well be partly a negotiation dialogue, or a deliberation type of dialogue, involving the making of prudent decisions for or against a particular course of action (in this case represented by the bill or measure being debated). Much here may depend on the stage the bill has reached-whether it is in a first or second reading, for example-in the legislative process.

Despite these problems, however, the example from Copi is not a bad one, in that it does give a fairly clear and common (if sketchy) case where the failure of logical relevance is of a kind that fits in with what could be described as a failure to meet requirement (R3) of a persuasion dialogue. If we view the legislator's speech in this case from a viewpoint that the normative model of the persuasion dialogue represents the type of dialogue, then the logical irrelevance exhibited by his argument can be explained and evaluated as a failure to meet one of the requirements for successful argumentation in a persuasion dialogue. While appearing to meet the normative model of persuasion dialogue, the dialectical and material irrelevance displayed by his argument can be explained as a fallacy, on the grounds that it fails to meet one key requirement while appearing to meet the other three appropriate requirements of persuasion dialogue.

\section{The Method of Argument Extrapolation}

The example used by Copi to illustrate the fallacy of irrelevant conclusion was problematic in several important respects, but it is an evocatively familiar type of case that does suggest very plausibly a common tactic of deceptive argumentation that is well worth being aware of. The central problem is how material relevance of the kind that fails in this example can be modelled precisely in the persuasion type of dialogue. The solution is to provide a way of implementing the requirements (R1) to (R4), as applied to particular cases where material relevance and irrelevance is at issue. It is especially important to focus on (R3), to determine when, in a given case, this requirement has not been met adequately.

The general problem of evaluation posed by particular cases is that there is a thesis to be argued for, and there is a given line or direction of argument, representing the way the argument has gone so far in that case. The fallacy of irrelevant conclusion is committed when the textual details of the case can be used to document the claim that the direction of the argument is not moving towards the thesis 


\section{Douglas Walton}

to be argued for. Instead, it may appear that it is moving in a different directionperhaps one of evoking a positive attitude to gain the psychological relevance needed to persuade an audience. But the logical failure is that the conclusion to be proved (that is supposed to be proved, according to the conventions appropriate for the type of dialogue the participants are supposed to be engaged in) is not the same proposition the real argument in the case is being directed towards.

But how can we identify, analyze and evaluate arguments used in given cases to see whether they exhibit this particular sort of failure? The failure is not one of deductive validity of the kind traditionally addressed by logic. It is a dialectical failure of an argument to be used in a conventional type of dialogue to fulfill the goals appropriate for this type of dialogue by the means that should be used for this purpose. It is a pragmatic failure of the use of an argument in a context of dialogue.

The method used to determine dialectical relevance of the use of an argument in a given case, argument extrapolation, matches the given argumentation up to the conclusion to be proved by a process of forward and backward chaining, as indicated in Figure 1 (see next page).

The given argument, which is a localized sequence of argumentation, as attributed to the proponent in the particular case, is extrapolated forward to get an idea of where it seems to be leading. At the same time, if the conclusion to be proved globally has been made evident in the case (as it was in the legislator case), a backwards chaining extrapolation can be made, yielding an idea of what sorts of lines of argumentation would be required to establish this conclusion (from what we know of the type of dialogue involved, and the methods of argumentation needed to prove something in this type of dialogue). Then the question is: Do these two chains of argumentation meet up at some point in the middle or not? Is the forward chaining of the given argument a direction that shows promise of being useful for completing a line of argument moving towards the conclusion to be proved? Or is it moving in a different direction? It is the asking of these two questions, in relation to the information given in a particular case, that should determine whether the argument used in that case is dialectically (logically) relevant or not.

In any given case, once the argument diagram has been constructed for the case, using the method of argument diagramming, one can look over the pathways of argumentation exhibited in the diagram, and see whether the particular argument in question is part of a pathway that goes towards the ultimate conclusion that is supposed to be proved by the argumentation in the case. But if the argument is still at a mid-point, and the case is not closed, it may be hard to tell where the pathway of argumentation is leading. Also, in many cases, of the kind used in logic textbooks, not enough context is given to have a really good basis for judging where the line of argument might be leading. In such cases, the argument extrapolation can only be based on assumptions and conjectures. All a critic can do is base 


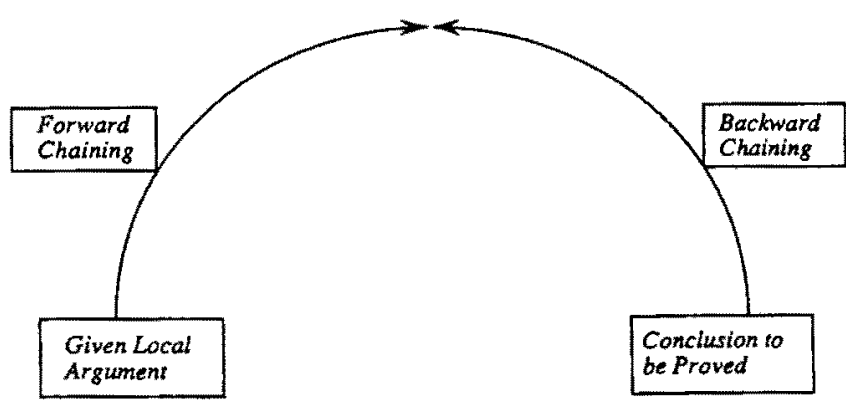

Figure 1.

an evaluation of an argument used in a particular case on the available evidence of the discourse given in the case.

Copi's legislator case seems more like a case of deliberation than persuasion dialogue, but the method of argument extrapolation seems to be applicable here, even though the details are very sketchy. Copi puts the test of relevance or irrelevance of the argument as follows: the question is whether the measure (the housing bill proposed) will provide "decent housing for all the people" and "if so, will it provide it better than any practical alternative?" The legislator's argument is judged to be irrelevant by Copi because his speech about "decent housing for all the people" does not show promise of presenting a line of argument that gives good reasons for thinking this particular bill will do the job, as opposed to any practical alternative. In this case, it may be presumed that the debate is on a particular bill, and that the legislator in the case is in favor of passing the bill. This context sets the thesis that the legislator is supposed to argue for. He is supposed to present arguments supporting this particular housing bill that will offer reasons to those opposed to the bill to change their opinion, and vote for it. His thesis is that this particular housing bill is a good one, meaning that it is a good piece of legislation that everyone in the legislative assembly ought to vote for.

A problem with Copi's example is its sketchiness, however. Not enough details of the legislator's speech, and the particular housing bill that has been proposed, have been given, of a kind that would enable a critic to judge just exactly how and why the legislator's argument fails to be useful in moving forward to the conclusion that the particular bill under consideration is a good solution to the housing problem (or not).

What really enables one to support the evaluation that the legislator's argument does not perform this function is Copi's evocation of what we know from personal experience is a favorite tactic of political speakers in legislative debates and other political speeches. According to Copi (1982, p. 111), "The speaker may have succeeded in evoking such a positive sentiment for housing improvement that the 
hearers will vote more enthusiastically for the bill proposed than if its passage had really been proved to be in the public interest." The tactic being used by the speaker in such a case is a familiar one we all recognize. More precisely, the account given of the speaker's use of emotions to rouse the enthusiasm of the audience indicates the fault can be located as a failure of (R4). The speaker is doing something else to win the approval of the audience for the bill he advocates-something other than using a chain of proper arguments of the kind required in a persuasion dialogue by (R1), (R2) and (R3). In providing a normative framework for evaluating the argument in this particular case as irrelevant, both (R3) and (R4) play a role.

But the sketchiness of the example presented by Copi leaves a lot to be desired if we really want to pin down the criticism that the legislator's argument is irrelevant. There doesn't seem to be enough data given for the method of argument extrapolation to get a good bite on the case. Testing an actual example would be more lengthy, but to get a bit further, this is the step that needs to be taken.

\section{Testing an Actual Example}

Actual cases comparable to the kind of case cited by Copi can be found in political debates in legislative assemblies. An illustrative case is provided by a debate on the Northumberland Strait Crossing Act in the Commons Debates of the Canadian House of Commons (Hansard, June 14, 1993, pp. 20729-20744). The purpose of this debate was to discuss, and to vote on, proposed amendments to the Northumberland Straits Crossing Act (Bill C-110) at the so-called "report stage" where the debaters are supposed to avoid irrelevance, and to address their comments to the question before the House (according to the rules of procedure for the Canadian House of Commons). The particular focus of this debate were amendments to the bill concerning the environmental impact of the proposed construction of a bridge, or "fixed link" between Prince Edward Island and the mainland of Canada.

The discussion of the proposed amendments was long and detailed, but about ten pages into the record of it, Jim Fulton, the member for Skeena, started to attack both parties in a derogatory way. He accused the Liberals of wanting to "squeeze and sleaze their way and get a few extra votes" in the region. And he accused the Conservatives of wanting "to use the fixed link as a banner to wave around the Maritimes saying they are going to do something big for all the voters out there" (p. 20738). Then Fulton launched into a personal attack on the leader of the Conservative Party at the time, Prime Minister Kim Campbell (pp. 2073820739).

It is like the person who has just become Canada's Prime Minister the hon. member for Vancouver Centre. She said before her campaign began that she had smoked marijuana. When asked during the leadership campaign she said she had smoked marijuana but she did not break any law by doing it. Every dean of law in the country said that was not true. If one smoked marijuana, one broke the law. 
Five hundred and thirty thousand Canadians have a criminal record for smoking marijuana. They are all supposed to keep their criminal records. They cannot get bonded jobs. They cannot do anything but it is okay. A person can be the Prime Minister of Canada and break the law. Also, you can say that because you are who you are you did not break the law.

Canadians are getting really sick of this stuff. I am getting really sick of it. There is one law for the grand elevated elite who sit on the government side as prime minister or whatever. The law applies only to the great unwashed. It applies to those Canadians who have to pay the taxes and the piper.

This particular argument doesn't really seem to be relevant to the debate as a whole, which is about a particular bill. Fulton's rousing attack on the "grand elevated elite" stands out from the rest of the debate on the Northumberland Strait Crossing Act, which continues for another six pages or so in Hansard. It seems to be an interjection. But his remarks are not completely irrelevant. He is suggesting that there is a pattern of unethical conduct and disdain for the law in the leading parties, and that the failure to conduct an environmental assessment for the impact of the bridge project is consistent with or comparable to this pattern of disdain shown by these two parties.

But is Fulton's attack on Campbell, for having admitted smoking marijuana in the past, ${ }^{7}$ materially relevant in the debate on the Northumberland Strait Act? This bill is the specific question to be addressed, and in particular, the question is whether the proposed amendments to it should be approved or not. For Fulton's attack on Campbell's marijuana smoking to be materially relevant, it must advance the line of argument on this question by connecting to it in some material way. But as one scans over the text of the debate, there appears to be no clear and convincing evidence of such an argument extrapolation. Fulton's comments are quite general and wide-ranging in nature, and do not give particular reasons for rejecting or reformulating any of the proposed amendments.

In this case, as opposed to the case from Copi, the issue of the debate is quite specific, and is stated with a fair amount of precision. So one can get a fairly clear idea of what kinds of arguments should be dialectically and materially relevant to the dialogue. Also, looking at the details of Fulton's interjection above, in the context of the actual debate that took place, it is quite possible to give documentable evidence of a failure of material relevance in the case.

Ultimately the test of material relevance in such a case is whether the actual argument given can be extrapolated forward so that it meets up with another line of argument that would give a good reason for accepting or rejecting the proposal being discussed. To apply the text is a contextual job. One has not only to look at the actual text of discourse-given, in this case in the fifteen pages of the transcript of the debate-but to judge from this text whether the argument cited (as quoted above) can move forward as a contribution to a persuasion dialogue (or deliberation) on the issue and connect up with the thesis the proponent is supposed to be establishing. To make the test, a critic has to look over the whole transcript 
of the case, and make an evaluation based on the evidence given in the sum total of the argumentation presented.

From a dialectical point of view of the requirements of a persuasion dialogue, the evidence in this case indicates that Fulton's argument was not materially relevant, in the sense required by requirement (R3). It may have appeared to be relevant, because it was part of a kind of ad hominem attack on the ethics of the Liberals and Conservatives. But the debate in this case was on specific proposed amendments to the Northumberland Strait Crossing Act-the bill being discussed. Thus the proponent, Fulton, was supposed to be bringing forward arguments for or against the specific amendments. The conclusion to be proved is that one or more of these proposed amendments is a good thing to vote for, or not. It is something else again to prove, or at least argue, that Kim Campbell smoked marijuana. What use could such an argument be to prove what Fulton was supposed to prove in the debate? None at all, it would seem. Hence given the evidence of the text of discourse and the dialectical context of the case, it would seem fair enough to criticize his argument on grounds of its questionable material relevance to the debate.

However, one can also look at relevance from the point of view of the rules of order for commons debates in Canada, ${ }^{8}$ and ask why the Speaker of the House failed to intervene and ask Fulton to get back on track. Probably the reason is that Fulton's interjection was not so lengthy that it seriously threatened to interfere with the discussion of the Northumberland Strait Crossing Act, given the time allotted to the reading stage of this bill. At any rate, Fulton's argument was not questioned by the Speaker on grounds of relevance. He was not asked to "get back on track," as sometimes happens in these debates.

But from a logical and dialectical viewpoint that would be appropriate for a persuasion dialogue, Fulton's arguments could be judged to be materially irrelevant in exactly the sense cited by the logic textbooks as constituting the fallacy of irrelevant conclusion. In this way, it is comparable to Copi's example. In that case, as well, the debate was supposedly on a specific housing bill, and the legislators' speech simply failed to give any real reason to vote one way or the other. The difference with the Fulton case is that, being an actual case, it takes a much more detailed analysis of the text of the debate to apply the test of argument extrapolation. But on the other hand, the test can be applied in a more decisive way that utilizes a larger body of evidence.

\section{How the Method Should be Applied}

In evaluating a case like the marijuana argument above, one needs to be careful. The argument is a personal attack on the ethics of the leader of the Conservative Party, and as such can be classified as an ad hominem argument, in the usual terminology for traditional fallacies. The second part of Fulton's argument, where he talks about the "grand elevated elite," and how "the law applies only to the great 
unwashed," could be classified as an argumentum ad populum, or "appeal to the people" type of argument. From the traditional point of view then, the standard treatment would be to see Fulton's argument as fallacious, because it uses these two types of argumentation, traditionally classified as fallacies. But recent work (Walton, 1989) has shown that neither of these two types of argumentation is inherently fallacious. Indeed, in political debate, character is (in some cases) a relevant, and even a very important, issue. And in a democratic system of government, appeal to the people, or to popularly accepted views, can be quite a reasonable type of argumentation generally even though it (like the ad hominem) is subject to abuse. On grounds of these traditional classifications alone then, it would be too much of a logical leap to evaluate the marijuana argument as irrelevant, simply because the ad hominem and ad populum types of argument are used in it. Instead, the evaluation should be made the other way around. One of the most important criteria for evaluating arguments of these types as fallacious (in some cases) is that the argument, as used in the given case, is not materially relevant.

Also, as noted in the account of the Northumberland Strait debate given above, it was part of the larger chain of argumentation in Fulton's speech to attack both the Conservative and Liberal parties by attacking their ethics, using words like 'sleaze,' and accusing them of showing disdain for the law. In context then, the marijuana argument is relevant in the sense that it does fit in with the over-all direction and strategy of what appears to be Fulton's general line of argument. And questioning the ethics of those who hold opposed views, or appealing to popular opinions, as noted above, can be relevant in a political debate.

So what evidence can and should be given then, to support the charge that the marijuana argument is irrelevant? Several steps are needed to provide such evidence. The first step is to ask what type of dialogue the participants are supposed to be engaged in. It is a House of Commons Debate in Canada, which means that the dialogue is in an institutional framework, and is a particular debate with a purpose in a democratic system of legislation-a debate that is ruled by a Speaker, using codified rules of procedure. There are rules requiring relevance, but they are quite general, and are not very often used by the Speaker. ${ }^{9}$

Can we look at such a debate from a logical point of view, and judge an argument in it to be materially irrelevant on logical grounds? Some would say that logic has nothing to do with political debate, and that to expect politicians to be logical in debating is hopelessly nairve. But surely if a democratic system of legislation is to be defended as part of a system of government that can at least sometimes lead to informed and wise choices, some standards of relevance of a logical sort can and should be applied in evaluating or criticizing argumentation in political speeches. So it could be legitimate to look at an argument in a political debate from the viewpoint of a normative model of dialogue, like that of a persuasion dialogue, and then evaluate the argument according to the standards and requirements of that normative model. Such an evaluation could be informative and useful, provided it 
is clear that it is being conducted from a particular standpoint, according to standards of rational argument appropriate for that standpoint. The next step is to turn to the details of an argument used in a particular case, and to determine, using the textual evidence, whether the requirements were met or not by the argumentation given in that case.

Applying the method of argument extrapolation is done by taking the particular argument at issue, and determining its premises and conclusions (at the local level). In this case, Fulton's argument starts out as an argument from analogy-"It is like the person..."-citing a case where the Prime Minister admitted doing something that was illegal. He then uses this argument-a type of personal attack-to lead into a second argument to the effect that the "grand elevated elite" are above the law that applies to the ordinary person. The question is whether this argument can be extrapolated forwards in a chain of argumentation that has as its conclusion the proposition that the Northumberland Strait Crossing Act is defective-and in particular that one of the proposed amendments to the act is not good legislation. This test, it needs to be emphasized, is one of dialectical and material relevance.

The kinds of skills needed to apply this test incorporate many of the techniques of argument diagramming already in use in argument reconstruction (Freeman, 1991; Snoeck Henkemans, 1992; Walton, 1996). As indicated in Section 2. above, the new method of argument diagramming set out in (Walton, 1996, Chapter 6) contains the concept of a pathway of reasoning, and this concept is the fundamental tool that should be used to evaluate cases of arguments to assess the relevance of a line of argument in a given case. Using these methods, premises and conclusions of an argument are identified as particular propositions. In particular, lengthy sequences of argumentation are reconstructed as chained together sub-arguments, where the conclusion of one sub-argument becomes a premise in the next one. For purposes of evaluating argumentation for relevance, this technique needs to be extended, so that a given argument can be extrapolated forward, to test whether it can meet up with a line of argument that would prove or disprove a thesis at issue in a dialogue.

One problem with applying the test to a case of a materially irrelevant argument like the marijuana argument is that much of the evidence is negative evidence. It is the failure to find enough of a basis for such an argument extrapolation, after having gone over all the text of discourse of the dialogue, that is the evidence for evaluating the argument as irrelevant. Much of the focus in informal logic has in fact been on evaluating argumentation on the negative basis of criticizing arguments as fallacious. However, this negative aspect is not essential to the method of argument extrapolation. It can as well be used to show how an argument is materially relevant, as used in a given case, in a context of dialogue. So it could be equally well used to defend an argument from the criticism that it is irrelevant. 


\section{Questions Raised}

The analysis above has picked out this one particular type of example of the fallacy of irrelevant conclusion as the sort of case to be studied because (R3) does appear to pick out or indicate this type of failure as what the requirement is excluding. Thus the question is raised whether particular fallacies are associated with violations of particular rules. Perhaps, one might hypothesize, (R3) is the "rule of relevance," so that all failures of dialectical relevance are excluded by this rule. These observations raise a number of questions.

What seems to be an (at least somewhat) separate fallacy of irrelevance is the so-called red herring fallacy, where an arguer not only argues for the wrong conclusion, but tries to throw the audience off track (off the proper line of argumentation leading to the right conclusion) by going in a different and distracting direction. Some elements of this use of a tactic of distraction are evident in both cases studied above. Is this tactic a separate fallacy of relevance, or is it a kind of extension of the fallacy of irrelevant conclusion? It seems that the red herring fallacy involves a failure to meet (R3), but it also involves using a different line of argument, a distraction of the kind that would come under the heading of (R4), i.e., using other means than a proper chain of argumentation meeting requirements (R1), (R2) and (R3).

So do we have one fallacy of irrelevance here, or two? Another problem is that many logic textbooks, like Copi (1982), include many other kinds of arguments thought to be fallacious, like the ad hominem and ad populum as being failures of relevance. Hence it becomes problematic whether a single fallacy is associated with a single rule, so that there is a one-to-one correspondence between the fallacies and rules for persuasion dialogue, or critical discussion, or some other type of dialogue.

What remains however is that there is a fairly good match, or at least a kind of mirroring or correspondence, between (R3) and the fallacy of irrelevant conclusion, as characterized above. The rule does state a general requirement for argumentation in a persuasion dialogue that does both explain and exclude what has centrally gone wrong in a case where the fallacy of irrelevant conclusion has been committed. It tends to support the theory of van Eemeren and Grootendorst (1984; 1987) that fallacies are essentially violations of the rules of a critical discussion, and that the fallacies can be paired with violations of particular rules. For the critical discussion would appear to be a type of persuasion dialogue, and both appear to have more or less the same requirement of relevance.

But now some questions need to be raised on how close the match is between (R3) and the fallacy of irrelevant conclusion. In Copi's example, the assumption made was that the premise, "Housing for all is desirable," does not appear to be leading along any pathway that has the legislator's thesis in the debate as its ultimate conclusion. As a practical inference that would be structurally correct, we could reconstruct the legislator's argument as follows. 
(PI) Housing for all is desirable.

The proposed legislation is the best available means for procuring housing for all.

Therefore, the proposed legislation should be adopted.

Reconstructing the line of argument in this way appears to make it able to meet the requirement set in place by $(R 3)$, even though the argument is incomplete. And in fact, if his argument was criticized as irrelevant, this defence might be the very line of reply to the criticism that the legislator might take up. But would such a line of defence be convincing, as a justification of the claim that the legislator's argument is really relevant after all? It probably would not be, but why not? The answer to this question may indicate that it is not the violation just (R3) that leads one to think that the legislator's argument should be criticized as a fallacy of irrelevance, but some other rule violation is involved as well.

Such a criticism can be sketched out as follows. The problem with the legislator's argument is that the first premise of (PI) the statement that housing for all is desirable, was presumably already in the commitment of everyone involved in the debate, and so bringing in the argument of the form (PI) didn't make any advance. If we were to suppose instead that everyone agreed with the second premise, that legislation is the best means, but if many doubted the first premise, that housing was an appropriate goal, then the legislator's argument would not have been irrelevant at all. But since nothing was said by the legislator (as far as we are told) to support the additional premise abut legislation being the best means, there was no advance of the argument on that side. Since the legislator failed to back up an argument of the form (PI) in the appropriate way, by supporting the premises, his argument made no advance towards the conclusion to be proved, namely that this legislation should be adopted.

The failure indicated by the above criticism relates to the failure of advance of the line of argument based on a premise that everyone accepts anyway, and that would therefore appear to be useless to persuade the opponents of the housing bill to accept the conclusion that they should vote for it. It's not just that this premise fails to be on a pathway that leads to the conclusion to be proved, but that the pathway of the kind that this is on is not really being used to prove something to the audience that they doubt. The failure with the argument (PI) is that it is no advance, in the sense that it is not being used to overcome the doubt of the other legislators by taking some premise that they already accept, or can be gotten to accept, and then using that premise to get them to accept something else (the conclusion that this legislation should be adopted). This criticism is based on a failure of the probative function of an argument, whereby the premises are used by the proponent to shift a weight of acceptance forward so that the conclusion, which was previously not acceptable to the respondent, now becomes acceptable. The probative function represents the use of an argument to overcome a respondent's initial doubt, so that the respondent will become committed, in virtue of how the argument was used, to its conclusion. 
So it may be that (R3) alone, or in conjunction with the other three requirements of the successfulness of an argument in a persuasion dialogue given in Section 1., cannot handle all aspects of why the argument in Copi's example is thought to be a fallacy of relevance. In addition, the probative function also needs to be taken into account. An argument is dialectically irrelevant not just because it does not extrapolate forward to reach the conclusion it is supposed to prove, by some pathway of reasoning that could be used. The failure is more than this. It is that a pathway does not lead to this conclusion that represents a line of argumentation that could be used to fulfill the probative function by removing the respondent's doubt about this conclusion. In short, there are some questions raised by this way of viewing the criticism of the legislator's speech in Copi's example that suggest that failure to meet (R3) may not be the whole story of how to explain and evaluate cases of the fallacy of irrelevant conclusion. The probative function may have a role to play in this story as well.

Some other interesting questions are also raised about the modelling of relevance in formal systems of dialogue. A simple system of persuasion dialogue, using only the four requirements (R1) to (R4), could easily be implemented as a framework for argumentation between a user and a computer program-of a familiar kind, like an expert system containing a set of facts and rules-where the user tries to get the system to accept her thesis by putting forward arguments to prove that thesis, based on propositions in the commitment set (the set of facts and rules) of the system. Such an artificial intelligence modelling of argumentation in persuasion dialogue would be an interesting way to study fallacies of relevance.

Other questions relate to the application of a formal system of persuasion dialogue to realistic cases, like the Northumberland Strait Act case above, to test out the argumentation used in the case to see whether it can be judged to be materially relevant or not. These questions involve many of the same kinds of problems widely discussed in the use of argument diagramming for argument reconstruction.

\section{Notes}

'Support for this work was provided by a Research Grant from the Social Sciences and Humanities Research Council of Canada. Thanks are also due to the Philosophy Department of the University of Western Australia for providing support and facilities. I would also like to thank the participants in a discussion during an invited talk I gave on relevance at Murdoch University in Perth, Australia on November 25, 1996. I would like to acknowledge the support given by the University of Oregon during my term as Distinguished Visiting Professor at the Oregon Humanities Center in the spring of 1997, and the support given by the Department of communication Studies at Northwestern University during my term as Senior Fulbright Fellow in the first quarter of 1999.

${ }^{2}$ The term 'dialectical' as used in argumentation theory is different from the Hegelian-Marxist use of it. According to Hamblin (1970, pp. 254-255) formal dialectic is the construction of systems of dialogue to evaluate arguments put forward in a context of use. One of the main uses of dialectic, according to Hamblin, is the analysis of fallacies. 
${ }^{3}$ Persuasion dialogue is modelled as a dialectical system in Walton and Krabbe (1995).

4 This account is a simple sketch of the basic elements of a persuasion dialogue. More details are given in Walton and Krabbe (1995, chapter 4).

s Ways of dealing with this complication are implemented by the more complex structures of persuasion dialogue in Walton and Krabbe (1995).

${ }^{6}$ Hamblin (1970, chapter 1).

7 There is no evidence that she denied inhaling the marijuana.

${ }^{8}$ These rules are printed in the Précis of Procedure (House of Commons: Canada), 2nd ed., Ottawa, Table Research Branch, Clerk of the House of Commons, 1987.

${ }^{9}$ For example, at the third reading of a bill, debate is "irrelevant that is not strictiy confined to the elements of the bill" (Précis of Procedure, 1987, p. 78).

\section{References}

Aristotle. On Sophistical Refutations. Trans. E. S. Forster, Loeb Classical Library, Cambridge, Mass., Harvard University Press, 1928.

Aristotle. Topica. Trans. E. S. Forster, Loeb Classical Library, Cambridge, Mass., Harvard University Press, 1939.

Berg, Jonathan. "The Relevant Relevance," Journal of Pragmatics, 16, 1991, 411-425.

Copi, Irving M. Introduction to Logic, 6th ed. New York, Macmillan, 1982.

Dascal, Marcelo. "Conversational Relevance," Journal of Pragmatics, 1, 1977, 309-328.

Eemeren, Frans H. van and Grootendorst, Rob. Speech Acts in Communicative Discussions. Dordrecht, Foris, 1984.

Eemeren, Frans H. van and Grootendorst, Rob. "Fallacies in Pragma-Dialectical Perspective," Argumentation, 1, 1987, 283-301.

Eemeren, Frans H. van and Grootendorst, Rob. Argumentation, Communication and Fallacies. Hillsdale, N. J., Erlbaum, 1992.

Eemeren, Frans H. van and Grootendorst, Rob. "Relevance Reviewed : The Case of Argumentum Ad Hominem," Argumentation, 6, 1992a, 141-159.

Fowler, Thomas. The Elements of Deductive. Oxford, Clarendon Press, 1895.

Freeman, James B. Dialectics and the Macrostructure of Arguments. Berlin, Foris, 1991. Hamblin, Charles L. Fallacies. London, Methuen, 1970.

(Hansard) Canada: House of Commons Debates. Ottawa, Queen's Printer.

Jevons, W. Stanley. Elementary Lessons in Logic. London, MacMillan and Co., 1878.

Snoeck Henkemans, A. F. Analyzing Complex Argumentation. Amsterdam SICSAT, 1992.

Sperber, Dan and Wilson, Deidre. Relevance: Communication and Cagnition. Cambridge, Mass., Harvard University Press, 1986.

Walton, Douglas. Topical Relevance in Argumentation. Amsterdam, Benjamins, 1982. Walton, Douglas. Informal Logic. Cambridge, Cambridge University Press, 1989.

Walton, Douglas. Argument Structure: A Pragmatic Theory. Toronto, University of Toronto Press, 1996.

Walton, Douglas. Argumentation Schemes for Presumptive Reasoning. Mahwah, N.J., Erlbaum, 1996a. 
Walton, Douglas. The New Dialectic: Conversational Contexts of Argument. Toronto, University of Toronto Press, 1998.

Walton, Douglas N. and Krabbe, Erik C. W. Commitment in Dialogue: Basic Concepts of Interpersonal Reasoning. Albany State University of New York Press, 1995.

Douglas Walton, Department of Philosophy, University of Winnipeg Winnipeg, Manitoba, Canada R3B 2E9

Walton@Io.uwinnipeg.ca 